\title{
Carbon Black Polymer Sensor Array for Incipient Grain Spoilage Monitoring
}

\author{
Md. Eftekhar Hossain • Michael S. Freund • Digvir S. Jayas • Noel D. G. White • \\ Cyrus Shafai · Douglas J. Thomson
}

Received: 27 September 2011 / Accepted: 14 November 2011/Published online: 25 January 2012

(C) NAAS (National Academy of Agricultural Sciences) 2012

\begin{abstract}
Sensor arrays are currently used for classifying liquors, perfumes, and the quality of food products by mimicking the mammalian olfactory system. The use of this technology for the monitoring of stored grains and identifying the source of spoilage is a new application, which has the potential for broad economic impact. Carbon black polymer sensor array was fabricated and optimized for monitoring of incipient grain spoilage in a simulated stored grain bin. Various aspects of sensor array (flow rate, relative humidity, temperature, presence of background gas) were evaluated at stored grain conditions. Sensor response at low concentration (2\% of vapour pressure) of 1-octanol, 1,4-benzoquinone, acetone was checked in presence of water vapour and $400 \mathrm{ppmv} \mathrm{CO}_{2}$ as background. Slightly variable sensor responses were observed compared to in absence of background gases. The responses were decreased by $6-15 \%$ on an average for poly(vinyl acetate), poly(bisphenol-A-carbonate) and poly(vinyl butaryl) sensor while exposed in presence of 50\% water vapour. Polymers with high sensitive to background gases $\left(\mathrm{H}_{2} \mathrm{O}\right.$ and $\left.\mathrm{CO}_{2}\right)$, such as PVP and P4VP were excluded from the array in this study. Co-polymers with styrene showed low sensitivity drop compared to non-styrene copolymers based on 9 months observation. Therefore, styrene copolymer sensors were best suited to build a stable sensor for the sensor array. Selected polymers for the sensor array retained their sensing properties despite being stored under a wide range of temperatures $\left(-20\right.$ to $\left.25^{\circ} \mathrm{C}\right)$. The sensor array could recognize pure wheat as well as was able to determine the presence of red flour beetle on it.
\end{abstract}

Keywords Incipient grain spoilage $\cdot$ Carbon black polymer sensors $\cdot$ Sensor arrays $\cdot$ Odour volatiles

Md. E. Hossain · D. S. Jayas ( $ه)$

Department of Biosystems Engineering, University of Manitoba, Winnipeg, MB R3T 2N2, Canada

e-mail: digvir_jayas@umanitoba.ca

\section{S. Freund}

Department of Chemistry, University of Manitoba, Winnipeg, MB R3T 2N2, Canada

N. D. G. White

Agriculture and Agri-Food Canada, Cereal Research Centre, 195 Dafoe Road, Winnipeg, MB R3T 2M9, Canada

M. S. Freund · C. Shafai · D. J. Thomson Department of Electrical and Computer Engineering, University of Manitoba, Winnipeg, MB R3T 2N2, Canada

\section{Introduction}

In a recent Food and Agricultural Organization cereal production analysis, it was reported that $22 \%$ of world cereal production was carried over into the following seasons, the highest level since 2002 [5]. The prolonged storage of grains requires special attention because grains are a perishable commodity subject to loss resulting from organisms such as insects, mites, and fungi. Any loss in quality or quantity of the grain produced can result in significant economic loss for farmers or storage managers.

There are a wide variety of odour volatiles present in a grain bin [18] depending on surrounding conditions around stored grain. Some volatiles are present in high concentration, while others are at very low concentration; some are stable over a period of time, while others are unstable 
or degradable. Therefore, the choice of indicator volatiles requires careful consideration and should focus on volatiles that are reasonably stable and are at relatively high concentrations. For example, quinones are defensive secretions produced by red flour beetles in storage environments $[12,13,33]$. Several researchers $[2,16]$ monitored fungal volatiles, mostly alcohols and ketones using gas chromatography-mass spectrometry (GC-MS).

In addition to release of organic volatiles, grain bulks also produce carbon dioxide $\left(\mathrm{CO}_{2}\right)$ and water $\left(\mathrm{H}_{2} \mathrm{O}\right)$ vapour, usually generated due to respiration of grains, mites, insects and degradation of grain kernels by moulds. Measuring of $\mathrm{CO}_{2}$ and $\mathrm{H}_{2} \mathrm{O}$ concentration could be a very good tool for monitoring of gain quality.

On-farm stored-product monitoring techniques (physical and chemical) for the detection of insect, mite or fungal infestation have been described by several authors $[9,19$, $29,30,32]$. While each technique has certain advantages, significant limitations necessitate the development of useful sensors that can monitor incipient grain spoilage and could have a significant impact on grain storage systems. Human perception through the sensory systems is the oldest and still the most effective means to detect grain quality. A properly trained and efficient human sensory system can recognize and adapt to odours generated from grain. However, this approach can be risky and hazardous for human health. In both developing and developed countries, grains are checked for off-odours upon delivery at grain handling and storage facilities. The qualitative nature of these assessments and potential negative health impact are necessitating replacement of human perception by instrumental methods.

For monitoring insect volatiles [1, 10, 17, 31, 33] ultraviolet-visible spectroscopy (UV-Vis), polarography, thin-layer chromatography and gas chromatography have been used. These techniques involve a number of steps and are cumbersome and time-consuming. Therefore, a quick method to detect incipient spoilage could prevent major losses as a result of mould infection or insect infestation of stored grain due to poor storage management.

The sensor arrays combined with pattern recognition techniques offer interesting alternatives. The use of intrinsically conducting polymer [6] and conducting polymer composite sensors [26] are widespread in sensing applications such as to classify various liquors, perfumes, tobacco brands and beers [7, 20,23]. Carbon black polymer sensor is easy to prepare, inexpensive, resistant to poisoning $[4,24]$ and has high longevity compared to metal oxide based sensors. An array of such sensing elements produces a chemically reversible diagnostic pattern of electrical resistance changes upon exposure to different odourants. This characteristic of a sensor array can be used as a signature of odour volatiles using principal component analysis. Recently, a research team at the University of Manitoba developed a sensor for monitoring of $\mathrm{CO}_{2}$ in wheat [21, 22] using polyaniline boronic acid (PABA) [3], which could detect $\mathrm{CO}_{2}$ up to $2,455 \mathrm{ppm}$ in presence of relative humidity $(20-70 \%)$.

The primary objective of this research was to assess the potential for using carbon black polymer sensor array technology for detection of incipient spoilage of wheat by red flour beetle, Tribolium castaneum (Herbst).

\section{Materials and Methods}

\section{Materials}

For the fabrication of polymer composites, fourteen different insulating polymers (Table 1) were used. All polymers were purchased from Polysciences Inc. (Warrington, PA, USA) or Aldrich Chemical Co. (Madison, WI, USA) and were used as received. For the optimization of sensor array, the model volatiles used in this study were toluene, anisole, methanol, 2-propanol, 1-octanol, acetone, 1,4-benzoquinone and tetrahydrofuran; all were reagent grade and were used as received from EM Scientific (Carson, NV, USA) and Aldrich Chemical Co. (Madison, WI, USA). The carrier gas was oil free ultra high purity $(99.99 \%)$ compressed nitrogen from Praxair Inc. (Calgary, AB, Canada).

\section{Instrumentation and Apparatus}

Micro bubbler bottles of 500-ml capacity with two armed 29/34 ground joint (Lasalle Scientific Inc., Guelph, ON,

Table 1 Polymers used in the sensor arrays

\begin{tabular}{lll}
\hline ID $^{\text {a }}$ & Symbol & Polymer \\
\hline 1 & P4VP & Poly(4-vinyl phenol) \\
2 & PSAA & Poly(styrene-co-allyl alcohol) \\
3 & PMS & Poly(alpha-methylstyrene $)^{\mathrm{b}}$ \\
4 & PVP & Poly(N-vinylpyrrolidone) \\
5 & PVA & Poly(vinyl acetate) \\
6 & PMVE & Poly(methyl vinyl ether-co-malic anhydride) \\
7 & PBAC & Poly(bisphenol A carbonate) \\
11 & PS & Poly(styrene) \\
12 & PSMA & Poly(styrene-co-maleic anhydride) \\
13 & PVB & Poly(vinyl butaryl $)^{\mathrm{b}}$ \\
14 & PSu & Poly(sulfone $)^{\mathrm{b}}$ \\
15 & PMMA & Poly(methyl methacrylate) ${ }^{\mathrm{b}}$ \\
16 & PVCA & Poly(vinylidene chloride-co-acrylonitrile) \\
17 & PEO & Poly(ethylene oxide)
\end{tabular}

a Identification number

b Selected polymers for detecting volatiles by the sensor array 
Canada) were used to generate saturated vapour pressure. The measurements were performed at a temperature of $25 \pm 1^{\circ} \mathrm{C}$ over the course of the experiments described herein, 0-90\% RH based on applicability and the temperature was maintained using a microprocessor controlled water bath (Model No. 28L, Cole-Parmer, Montreal, QC, Canada).

Saturated vapour was carried out the sidearm of the bubbler, blended with a controlled background flow of pure carrier gas then transferred into a sensing chamber made of Teflon. The sensing elements were introduced into the chamber through open slot(s) and attached with the printed circuit board (PCB) connected through edge connector (Fig. 1). The chamber was sealed when connected with the PCB. The gas flow rates were controlled using mass flow controllers (Model: FLO-9HL, Plasmionique Inc., St. Hyacinthe, QC, Canada), three-way valves, and Teflon solenoid shut-off valves. Further information on instrumentation is reported elsewhere [22].

\section{Sensor Construction and Data Collection System}

Carbon black (CB) polymer sensors were prepared [26] on properly cleaned, inter digitated array (IDA) using composite of insulating polymers (Table 1) and carbon black. To obtain measurable film resistance (few kilo ohm), the composite mixture was sprayed several times on IDA and then dried in the room air of the lab for 1 day. The data collection system used for characterization of the sensor array consists of an Agilent 34980A Data Acquisition Switch Unit (Agilent Technologies, Inc., Santa Clara, CA, USA) using personal computer, where the data were stored

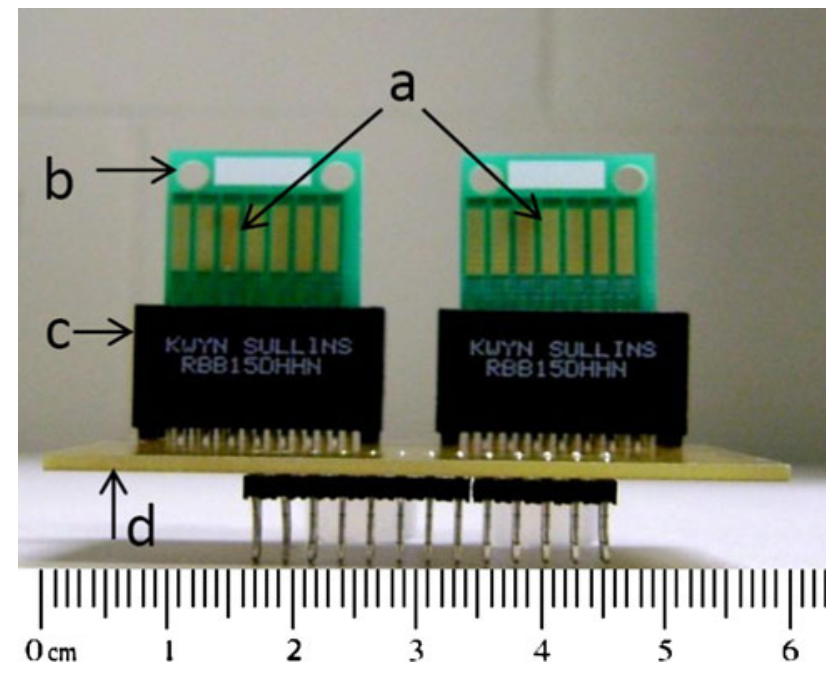

Fig. 1 A schematic representation of sensor array connected with edge connector. ( $a$ sensing electrodes; $b$ printed circuit board; $c$ edge connector; $d$ base) in a tab-limited text file (csv format). Then it was converted into $\mathrm{xl}$ format. The overall data were processed using MATCAD version 14.0 (Parametric Technology Corporation, Needham, MA, USA).

\section{Stored-Grain Volatile Monitoring}

Canadian Prairie Spring Red (CPSR) wheat was used for this study. One hundred grams of wheat at a moisture content of about $15-16 \%$ wet basis was used. The whole experiment was run at room temperature. A container (150 ml volume, $40 \mathrm{~mm}$ diameter, $120 \mathrm{~mm}$ long) was used to hold grain. Then the sensor array was assembled at the top of the container in such a way that there should not be any leakage. However, there was an opening at the top to insert grain and insect through a funnel when required. This opening was closed during experiments. It was assumed that there was minimum interference to the sensor response. Wheat and approximately 40-day-old 50 insects (red flour beetle) were used for the experiment. Red flour beetle were reared at $70 \% \mathrm{RH}$ and $25^{\circ} \mathrm{C}$ on wheat flour. Male-female insect ratio was not differentiated and it was assumed that 1:1 male-female ratio was present in the insect population. The responses were gathered until equilibrium with saturated vapour pressure of analytes at each stage of set concentration or relative humidity was achieved. Then the signals were processed and analyzed for interpretation.

\section{Sensor Selection}

Fourteen polymers and nine model volatiles were used to fabricate and select an effective sensor array for the monitoring of insect infestation in wheat as well as fungal infection. For down selecting an array of seven polymer sensors (Table 1), a set of statistical analysis was performed. Individual sensor performance was evaluated in terms of reproducibility (Fig. 2), sensitivity and selectivity with respect to model volatiles of interest. Scoring and ranking of sensors provided insight information and a statistical basis for selecting sensor materials from each sensor set. Selectivity was assessed based on weighted contribution of the sensors to linear discriminant analysis (LDA), reproducibility from relative standard deviations (RSD) of repetitive exposures, and sensitivity through linearity and slope of sensor responses as a function of concentration. These are all supervised methods for data analysis. Other methods such as principal component analysis (PCA), an unsupervised method, were also performed to gauge performance with multiple analytes, however this method did not provide additional insight into individual sensor performance. Details of supervised and unsupervised techniques of data analysis were described by Severin et al. [27]. 


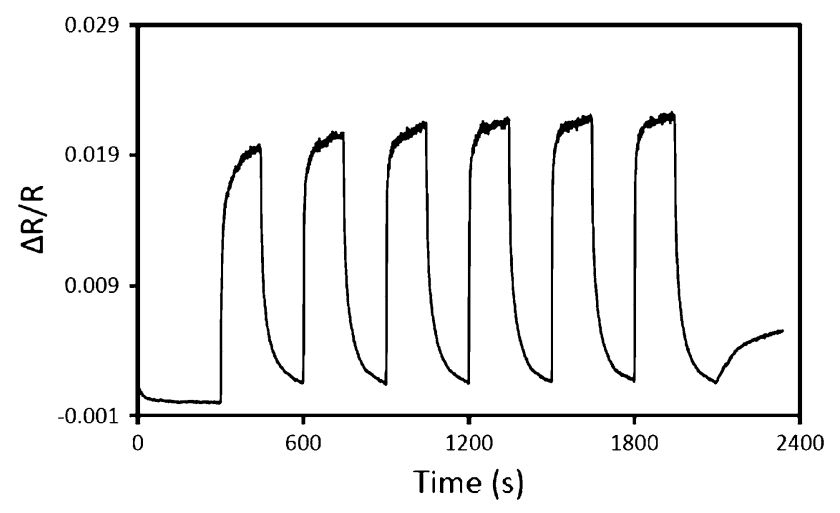

Fig. 2 Reproducibility $(N=6)$ of carbon black polymer sensorpoly(bisphenol-A-carbonate) to acetone at 0.02 partial pressure at a flow rate of $1,000 \mathrm{sccm}$ at $25^{\circ} \mathrm{C}$

\section{Results and Discussion}

\section{Validation of Sensor Selection}

A couple of sensor arrays were made using the best seven sensing polymers (PMS, PVA, PBAC, PS, PVB, PSu and PMMA) in terms of reproducibility, sensitivity and selectivity. Then the array was exposed to volatiles of interest and performed PCA using old Eigen vectors. The sensor arrays efficiently distinguished the analytes of interest along with other volatiles when they were exposed individually in the sensor arrays (Fig. 3). New exposures of volatiles to new sensor arrays fall within the same principal component space of previously determined using old sensor arrays.

\section{Stored Grain Conditions}

Geographical location of storage facilities plays a vital role in stored grain insect or fungal infestation development. In tropical regions (such as Bangladesh, Brazil, India, Mexico), infestations occur much faster than in cold or temperate regions (such as Canada, Russia, Sweden, Finland), where storage conditions are much cooler and drier all year round. Within a grain bulk, interactions occur among the living organisms and their nonliving environment. Deterioration of stored grain results from such interactions. There are a number of abiotic and biotic factors involved in insect infestation development in the stored grains. Abiotic variables are relative humidity, temperature, moisture content in the grain, carbon dioxide and other volatiles, site preparation, and bin structure; the major biotic variables other than grain in a grain bulk include fungi, bacteria, insects, mites, rodents, and birds. These pests rarely act alone. Their ecological kinships develop over the period of time with grain and amongst themselves, supported by certain other sets of variables in the complex process of (a)

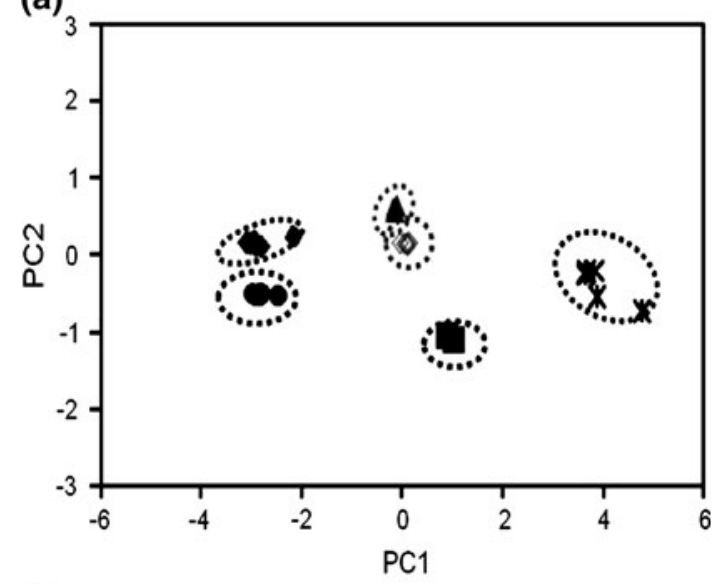

(b)

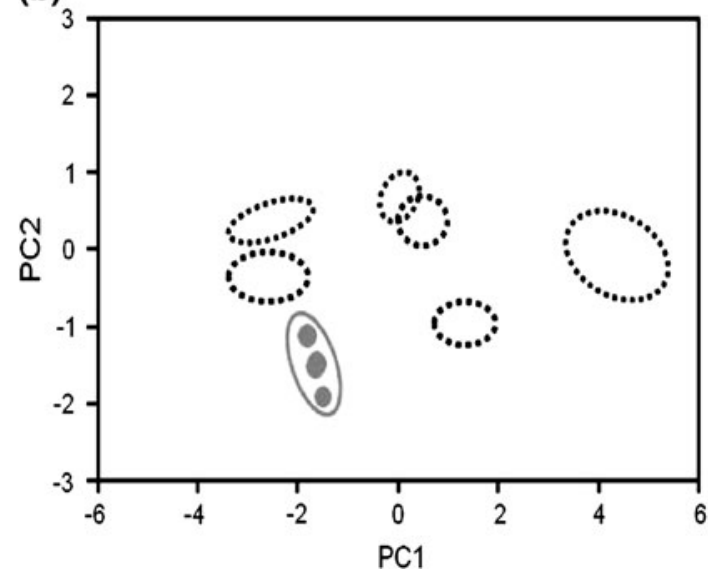

Fig. 3 Distribution of (a) model volatiles responses within two dimensional space using principal component analysis (PCA); (b) dynamic headspace wheat volatile response in the principal component space (grey solid circles and ellipse) (open diamond anisole; filled triangle toluene; filled diamond 1,4-benzoquinone; filled square methanol; asterisk acetone; filled circle 1-octanol)

deterioration of grain quality. Although spoilage is usually slow at the beginning, it may proceed very fast if the correct combination of variables are maintained in an undisturbed bulk [28]. Several studies [14, 15, 25] have been performed to understand the complex process of grain deterioration. For safe preservation of wheat, the rule of thumb is to store in clean storage structures at low moisture content (MC) below $14 \%$ and low temperature $\left(<15^{\circ} \mathrm{C}\right)$, as well as continuously monitor grain. For the monitoring of incipient wheat spoilage we have considered the following conditions in the lab: $0-90 \% \mathrm{RH},-20$ to $25^{\circ} \mathrm{C}, 15-16 \%$ MC wet basis and 50-1,600 standard cubic centimeter per minute $(\mathrm{sccm})$ flow rate to optimize sensor array.

\section{Sensor Array Optimization}

The optimization of a sensor array for incipient grain spoilage monitoring requires special attention to flow rate, 
linearity of sensor response, detector response to model volatiles in presence of background gases, aging effect, extreme weather conditions, random exposures of analytes to CB-sensors. Details are provided by Hossain [11].

\section{Effect of Flow Rate on Sensor Response}

Gas flow rate in a grain bin is very low unless it is being purged with ambient air for drying or cooling the grain. The gas circulation in a grain bulk proceeds predominantly through diffusion although additional mass transport through intergranular space can be caused by temperature gradients in the grain bin. Other factors, such as: externalwind flow and pressure, internal-moisture and $\mathrm{CO}_{2}$ by respiration of grain, insects, mites, fungi can also impact the process. As a result, the evolution of sensor array response patterns is expected to be slow, and constantly in equilibrium with its surroundings. To efficiently test the sensor arrays, a relatively high flow rate $(1,000 \mathrm{sccm})$ was chosen in designing and performing most of the experiments. Care was taken to allow sufficient time for the array to reach equilibrium with the exposed volatiles to assure that the response would be similar to that obtained for a similar concentration at a low flow rate.

\section{Detector Response in Presence of Background Gases}

Background gases present in stored grain are: $\mathrm{O}_{2}, \mathrm{CO}_{2}, \mathrm{~N}_{2}$, water vapor. Due to the high volatility of $\mathrm{O}_{2}$ and $\mathrm{N}_{2}$ sensors are insensitive to subtle variations in their levels. In the absence of water vapour $\mathrm{CO}_{2}$ showed almost no interference to carbon black polymer sensors and conducting polymer-PABA sensor [22]. But water vapour showed significant interaction with certain carbon black polymer sensors, for example the highest for PVP and the lowest for PMS. The PVP has the highest resistance variation in presence of $50 \% \mathrm{RH}$ and in the presence of $400 \mathrm{ppmv} \mathrm{CO}_{2}$. Presence of high relative humidity decreases overall response of certain volatiles (ethanol) compared to pure state [8]. They used polypyrrole sensor for this observation.

When sensors were exposed to low concentration ( $2 \%$ of vapour pressure) of 1-octanol, benzoquinone, acetone in presence of water vapour and $400 \mathrm{ppmv} \mathrm{CO}_{2}$ as background, variations in sensor responses were observed. The responses for acetone decreased by $10 \%$ for poly(vinyl acetate) sensor and $6 \%$ for poly(bisphenol-A-carbonate) (Fig. 4); whereas it decreased by $9-15 \%$ for both 1-octanol and benzoquinone in poly(vinyl butaryl) sensor while exposed in presence of $50 \%$ water vapour (Fig. 5). Polymers that were very sensitive to background gases $\left(\mathrm{H}_{2} \mathrm{O}\right.$ and $\mathrm{CO}_{2}$ ) such as PVP and P4VP were excluded from the array in this study.
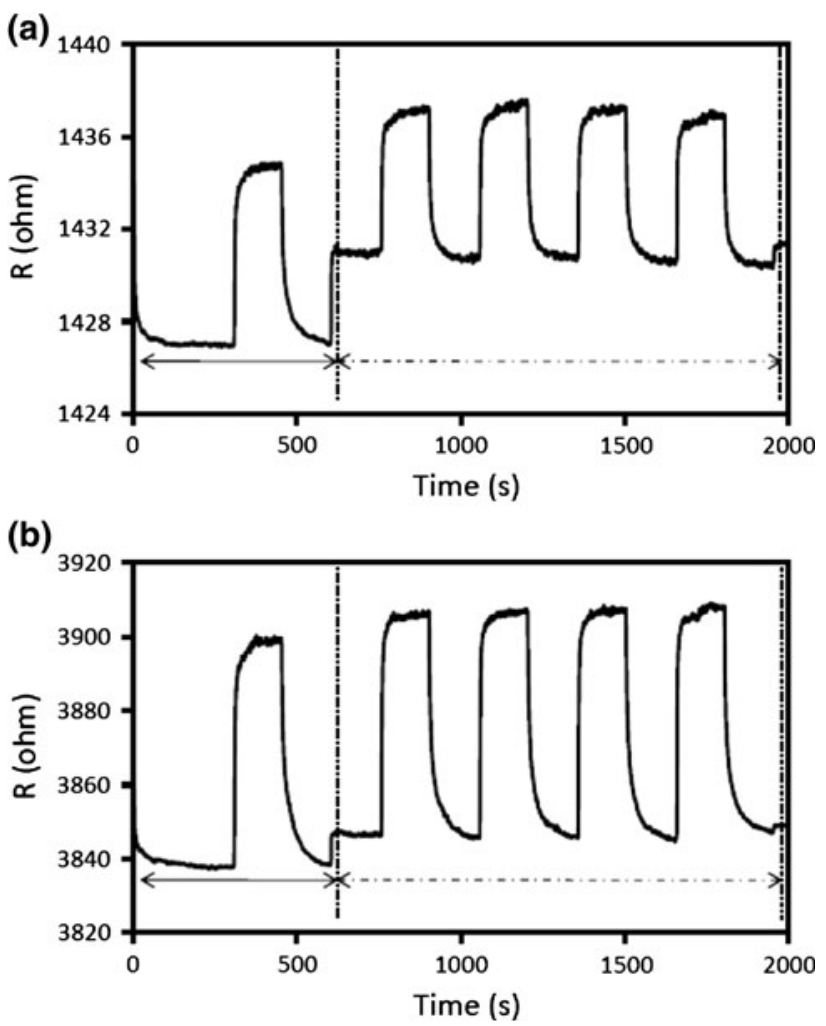

Fig. 4 Carbon black polymer sensor response to $2 \%$ vapour pressure of acetone in presence of background gases of $10 \%$ water vapor, 380 ppmv $\mathrm{CO}_{2}$ (left right dashed arrow), and in absence of background gases (left right arrow): (a) for poly(vinyl acetate) and (b) for poly(bisphenol-A-carbonate) polymer

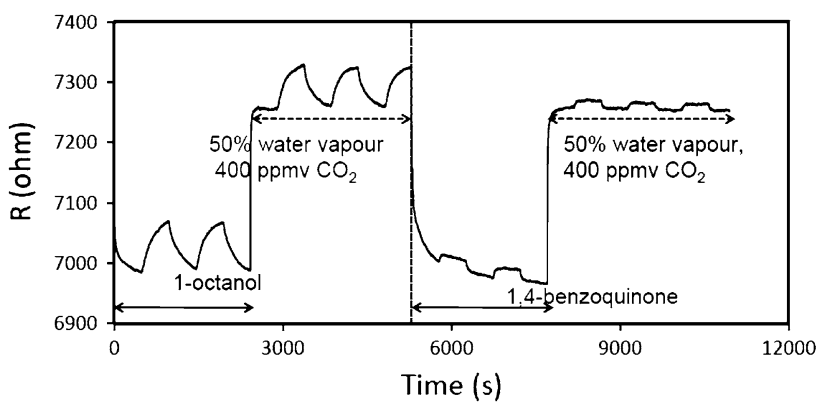

Fig. 5 Poly(vinyl butaryl) composite polymer sensor response to $2 \%$ vapour pressure of 1-octanol and 1,4-benzoquinone in presence of background gases, of $50 \%$ water vapor, $400 \mathrm{ppmv} \mathrm{CO}_{2}$ (left right dashed arrow), and in absence of background gases (left right arrow)

\section{Aging Effect}

One key advantage of organic polymer sensors is that they are robust and are not easily poisoned by reactive gases such as $\mathrm{H}_{2} \mathrm{~S}, \mathrm{SO}_{2}[4,24]$. The sensitivity of any sensor is expected to decrease over time due to exposure to various environmental conditions. Sensitivity of all carbon black polymer sensors was monitored using alcohol volatiles over 9 months. The sensitivity dropped between 5 and $85 \%$ 
for all polymers under observation. The selected sensor sensitivity for 1-octanol dropped maximum (27\% over a 9 months period); however the sensor array was still capable of differentiating 1-octanol from other volatiles. Co-polymers with styrene showed low sensitivity drop compared to non-styrene copolymers. Therefore, it was concluded that styrene copolymer sensors were best suited to build a stable sensor for the sensor array. Most of the non-styrene co-polymers were excluded from the sensor array while down selecting statistically.

Sensor Response After Exposure to Extreme Weather Conditions

Weather conditions across Canada and other temperate regions vary considerably over the year. Relative humidity varies from 20 to $100 \%$, and temperatures can vary from $-40^{\circ} \mathrm{C}$ (winter) to $40^{\circ} \mathrm{C}$ (summer). In order to determine whether CB-polymer sensors retain their sensing properties within this extreme temperature range, the fabricated sensors were stored at three different temperatures $(25,5$ and $-20^{\circ} \mathrm{C}$ ) for about $48 \mathrm{~h}$. Then the sensor array was brought into ambient condition and exposed to odour volatiles. Figure 6 shows response of selected polymers stored at various temperatures $\left(25,5\right.$ and $\left.-20^{\circ} \mathrm{C}\right)$. Normalized sensor responses previously exposed at three different temperatures were similar with exposure to acetone. Based on this observation it was concluded that these polymers retained their sensing properties despite being stored under a wide range of temperatures $\left(-20\right.$ to $\left.25^{\circ} \mathrm{C}\right)$.

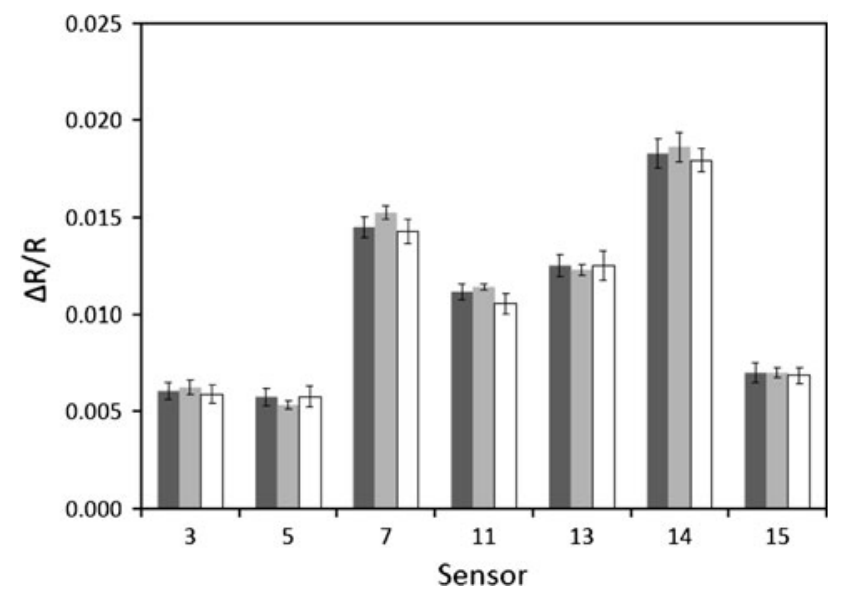

Fig. 6 Checking of functionality of carbon black polymer sensors at three different temperatures (filled square $25^{\circ} \mathrm{C}$, grey filled square $5^{\circ} \mathrm{C}$ and open square $-20^{\circ} \mathrm{C}$ ). The fabricated sensors were kept at three different temperatures $\left(25,5\right.$ and $\left.-20^{\circ} \mathrm{C}\right)$ for about $48 \mathrm{~h}$. Then the sensor array was brought into ambient condition and exposed to odour volatiles
Incipient Grain Spoilage Tracking Using Sensor Array

Figure 3 shows that head space volatiles from wheat occupy the space between methanol and 1-octanol and is well separated from quinone and benzene derivatives as well as acetone. Therefore, wheat does not itself produce volatiles indicative of insect (red flour beetle) infestation. Headspace volatile of wheat neither contain methanol nor 1-octanol; however a mixture of alcohols having high molecular weight was present. Severin et al. [27] showed that the distribution of homologous volatiles followed a general trend (low molecular to high molecular weight) within the principal component space. Our observation matched with his experimental evidence and trend. Principal component analysis was performed on the data shown in Fig. 7 to visualize the pattern differences between wheat alone and in presence of red flour beetle. Figure 8 shows the distribution of model volatiles sensor response and how the response varies from wheat, with and without red flour beetle adults.

The responses from wheat alone move towards the direction of aliphatic compounds especially towards the alcoholic compounds with high molecular weight, whereas in the presence of red flour beetle these move in the direction towards benzene derivatives. From this preliminary observation, it can be concluded that headspace of wheat volatiles may contain aliphatic hydrocarbon derivatives mixture with high molecular weight. Red flour beetle produces pheromones and other volatiles which are quite different from

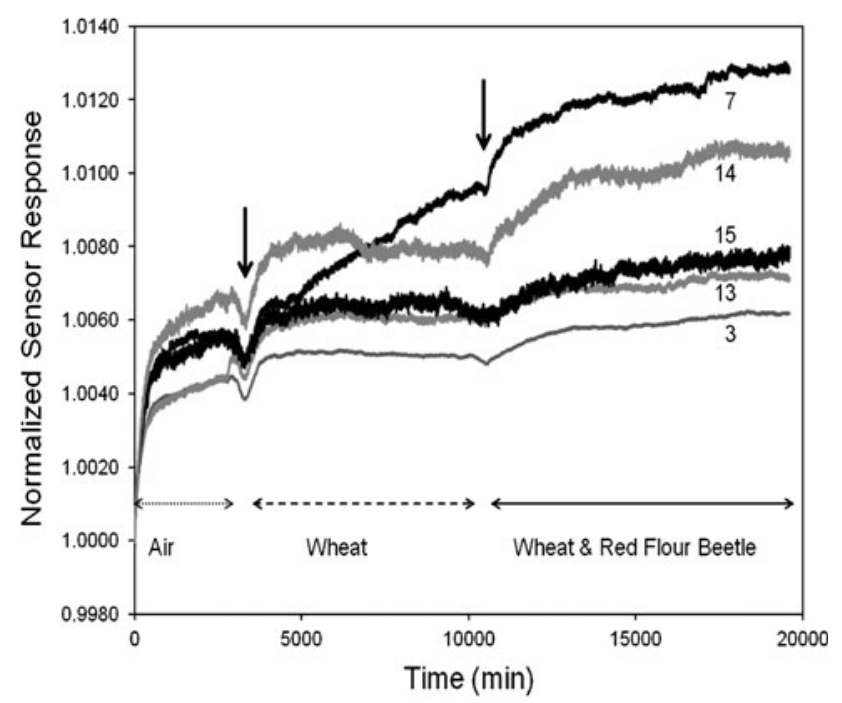

Fig. 7 Incipient spoilage detection using sensor array. (Left right dotted arrow) saturated vapour pressure of air; (left right dashed arrow) saturated vapor pressure from wheat volatiles; (left right arrow) saturated vapour pressure from red flour beetle pheromone on wheat. Down arrow indicates the region of sensor response when the model bin was opened for the insertion of wheat and red flour beetles. The numbers in the body of figure indicate various sensor responses 
(a)

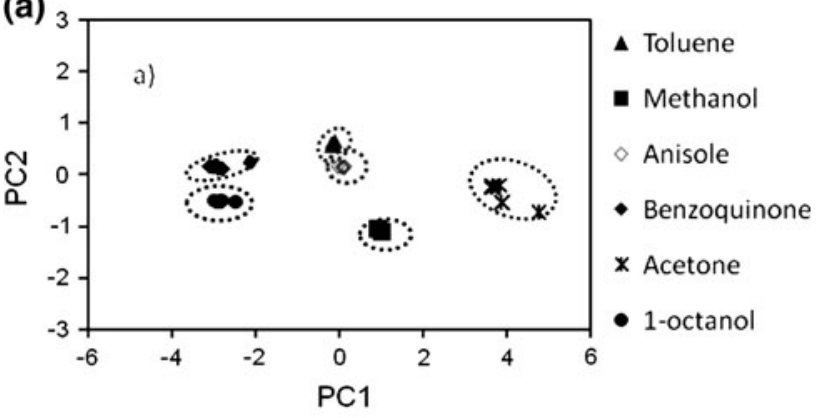

(b)

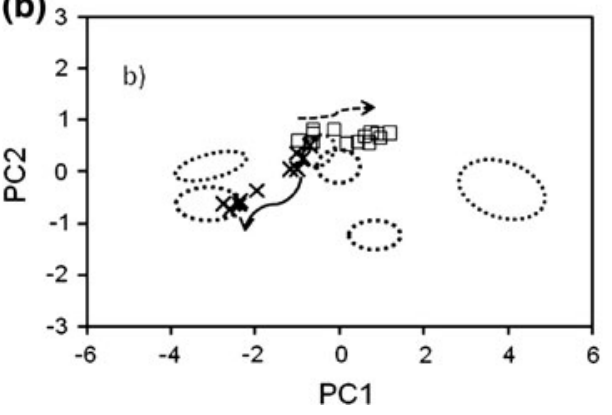

Fig. 8 Movement of the sensor array response within principal component space. (a) Two dimensional space distribution of model volatiles using old sensor array, (b) (rightwards arrow) movement of headspace volatiles from wheat, (rightwards dashed arrow) movement of headspace volatiles from red flour beetle secretions on (multiplication sign) pure wheat, (open square) presence of red flour beetle

pure wheat volatiles. These occupy the space in the region of quinones and benzene derivatives. Seitz and Ram [25] reported that Tribolium insect-infested headspace volatiles contain 1,4-dimethoxy benzene, 2-methyl-1,4-dimethoxybenzene and 2-ethyl-1,4-dimethoxybenzene that originated from quinone derivatives (MBQ and $\mathrm{EBQ}$ ). They proposed that the transformation might involve either photolytic or thermal process. Methyl radical formed in a stored-grain ecosystem might interact with benzoquinone or hydrobenzoquinone and might be methylated biologically during storage of grain.

Results of this study show that the sensor array can easily differentiate the presence of insects (red flour beetle) on wheat. However, the only concern of this experiment was that the insect population density was high. In Canada, there is a legal zero tolerance for the presence of insects in grain for human consumption; whereas two insects are allowed per kilogram of wheat in the USA. Red flour beetles are usually, present at the top $10 \mathrm{~cm}$ of the grain surface area and usually do not penetrate below the grain surface [34]. Therefore, a reasonably high population density is expected at the top compared to the rest of the grain in a large bin. It also ensures a high concentration of detectable headspace volatiles for the sensor array response.

\section{Conclusions}

The sensor array potentially classifies stored-grain volatiles with minimal interference from relative humidity. This study illustrates the application of a carbon black polymer sensor array for the detection of wheat spoilage due to the presence of red flour beetle by identifying volatiles from grain headspace with a one step process. The sensor array with further research and development may be made into a saleable product which may help farmers in taking preventive measures to save their agricultural commodities like wheat, barley, rice, and other cereals from red flour beetles. By saving grain it would contribute towards global food security and reduce pressure on global agricultural production. Utilization of the sensor array is a cost effective, healthy and environmentally friendly way for spoilage detection compared to human sensory use.

Acknowledgments The Natural Sciences and Engineering Research Council (NSERC) of Canada and the Canada Research Chairs (CRC) Program are gratefully acknowledged for funding this study.

\section{References}

1. Alexander P, Barton DHR (1943) The excretion of ethylquinone by the flour beetle. J Biochem 37:463-465

2. Borjesson T, Stollman U, Adamek P, Kaspersson A (1989) Analysis of volatile compounds for detection of molds in stored cereals. Cereal Chem 66:300-304

3. Deore BA, Freund MS (2009) Self-doped polyaniline nanoparticle dispersions based on boronic acid-phosphate complexation. Macromolecules 42:164-168

4. Dickinson TA, White J, Kauer JS, Walt DR (1998) Current trends in artificial-nose technology. Trends Biotechnol 16:250-258

5. FAOSTAT (2008) FAO statistical year book. Food and Agricultural Organization, United Nations, Rome, Italy. http://www. fao.org/. Accessed 20 Jan 2009

6. Freund MS, Lewis NS (1995) A chemically diverse conducting polymer based electronic nose. Proc Natl Acad Sci 92:2652-2656

7. Fukuda A, Nakamoto T, Moriizumi T, Asakura Y, Obigane Y (1991) Development of odour sensing system for application to whisky quality control. In: Technical digest of the 10th sensor symposium. The Institute of Electrical Engineers of Japan, Tokyo, pp 191-194

8. Gardner JW, Craven M, Dow C, Hines EL (1998) Prediction of bacteria type and growth phase by an electronic nose with a multi-layer perception network. Meas Sci Technol 9:120-127

9. Hagstrum DW, Flinn PW, Shuman D (1996) Automated monitoring using acoustical sensors for insects in farm-stored wheat. J Econ Entomol 89:211-217

10. Happ GM (1968) Quinone and hydrocarbon production in the defensive glands of Eleodes longicollis and Tribolium castaneum (Coleoptera, Tenebrionidae). J Insect Physiol 14:1821-1837

11. Hossain ME (2010) Fabrication and optimization of a sensor array for incipient grain spoilage monitoring. Unpublished MSc thesis, Department of Biosystems Engineering, University of Manitoba, Winnipeg, Canada

12. Howard RW (1987) Chemosystematic studies of the Triboliini (Coleoptera: Tenebrionidae): phylogenetic inferences from the defensive chemicals of eight Tribolium spp., Palorous ratzeburgi 
(Wissmann), and Latheticus oryzae Waterhouse. Ann Entomol Soc Am 80:398-405

13. Howard RW, Jurenka RA, Blomquist GJ (1986) Prostaglandin synthetase inhibitors in the defensive secretion of the red flour beetle Tribolium castaneum (Herbst) (Coleoptera: Tenebrionidae). Insect Biochem 16:757-760

14. Jayas DS (1995) Mathematical modeling of heat, moisture and gas transfer in stored grain ecosystems. In: Jayas DS, White NDG, Muir WE (eds) Stored grain ecosystems. Marcel Dekker Inc, New York, pp 527-568

15. Jayas DS, White NDG (2003) Storage and drying of grain in Canada: low cost approaches. Food Control 14:255-261

16. Kaminski E, Wasowicz E, Zawirska-Wojtasiak R, Gruchala L (1987) Volatile microflora metabolites as indices of grain deterioration during storage. In: Morton ID (ed) Cereals in a European context. Ellis Harwood, Chichester, pp 446-461

17. Ladisch RK, Ladisch SK, Howe PM (1967) Quinoid secretions in grain and flour beetles. Nature 215:939-940

18. Maga JA (1978) Cereal volatiles: a review. J Agric Food Chem 26:175-178

19. Mankin RW, Shuman D, CoVelt JA (1996) Noise shielding of acoustic devices for insect detection. J Econ Entomol 43:933-935

20. Nanto H, Kawai T, Sokooshi H, Usuda T (1992) Aroma identification using a quartz-resonator sensor in conjunction with pattern-recognition. Sens Actuators B Chem 14:718-720

21. Neethirajan S (2009) Development of a carbon dioxide $\left(\mathrm{CO}_{2}\right)$ sensor for agri-food industry. Unpublished $\mathrm{PhD}$ thesis, Department of Biosystems Engineering, University of Manitoba, Winnipeg, Manitoba, Canada

22. Neethirajan S, Freund MS, Shafai C, Jayas DS, Thomson DJ, White NDG (2010) Development of carbon dioxide sensor for grain quality monitoring. Biosyst Eng 106:395-404

23. Pearce TC, Gardner JW, Friel S (1993) An electronic nose for monitoring the flavor of beer. Analyst 118:371-377

24. Schaller E, Bosset OJ, Escher F (1998) Electronic noses and their application to food. Lebensmittel-Wissenschaft und-Technologie (Food Sci Technol) 3:305-316
25. Seitz LM, Ram MS (2000) Volatile methoxybenzene compounds in grains with off-odours. J Agric Food Chem 48:4279-4289

26. Severin EJ (1999) Array-based vapor sensing using conductive carbon black-polymer composite thin film detector. Unpublished $\mathrm{PhD}$ dissertation, Department of Chemistry, California Institute of Technology, Pasadena, CA, USA

27. Severin EJ, Doleman BJ, Lewis NS (2000) An investigation of the concentration dependence and response to analyte mixtures of carbon black/insulating organic polymer composite vapor detectors. Anal Chem 72:658-668

28. Sinha RN, Muir WE (1973) Grain storage: part of a system. AVI Pub. Co. Inc, Westport

29. Subramanyam B, Throne JE, Wright VF (1990) The development and use of pitfall and probe traps for capturing insects in stored grain. J Kansas Entomol Soc 63:506-525

30. Suzuki T, Mori K (1983) (4R,8R)-(-)-4,8-Dimethyldecanal: the natural aggregation pheromone of the red flour beetle, Tribolium castaneum (Coleoptera: Tenebrionidae). Appl Entomol Zool 18:134-136

31. Unruh LM, Xu R, Kramer KJ (1998) Benzoquinone levels as a function of age and gender of the red flour beetle, Tribolium castaneum. Insect Biochem Mol Biol 28:969-977

32. Vick KW, Mankin RW, Cogburn RR, Mullen M, Throne JE, Wright VF (1990) Review of pheromone-baited sticky traps for detection of stored-product insects. J Kansas Entomol Soc 63: $526-532$

33. Villaverde ML, Juárez MP, Mijailovsky S (2007) Detection of Tribolium castaneum (Herbst) volatile defensive secretions by solid phase microextraction-capillary gas chromatography (SPME-CGC). J Stored Prod Res 43:540-545

34. White NDG, Loschiavo SR (1986) Effects of insect density, trap depth, and attractants on the capture of Tribolium castaneum (Coleoptera: Tenebrionidae) and Cryptolestes ferrugineus (Coleoptera: Cucujidae) in stored wheat. J Econ Entomol 79: 1111-1117 